\title{
Urbanização e Impactos no Ciclo Hidrológico na Bacia do Mineirinho
}

\author{
Rubens de Miranda Benini ${ }^{1}$, Eduardo Mario Mendiondo ${ }^{1}$ \\ ${ }^{1}$ Departamento de Hidráulica e Saneamento, Universidade de São Paulo - USP, São Carlos/SP, Brasil
}

\begin{abstract}
RESUMO
Este trabalho teve como objetivo comparar cenários de ocupação urbana e seus efeitos no ciclo hidrológico da Bacia do Mineirinho. Buscou-se avaliar os riscos de enchentes causados pelo aumento das áreas de impermeabilização que tem ocorrido com a implantação do novo Campus da USP, São Carlos, SP. Foram estabelecidos quatro cenários de ocupação urbana: cenário pré-urbanização (1972); cenário 2000, cenário 2025 com Plano Diretor (CPD); e cenário 2025 sem Plano Diretor (SPD). Para comparação dos diferentes cenários realizaram-se simulações hidrológicas com modelo hidrológico IPH II. Pode-se observar que no cenário 2025 SPD a vazão máxima aumentou 388,0\% quando comparada ao cenário 1972 e 319,4\% quando comparada ao cenário 2000. Entre os cenários 2025 CPD e 2025 SPD há diminuição de 22,3\% na vazão máxima e aumento no tempo de pico é de 50 minutos. Mesmo com aplicação de diretrizes do PD os riscos de inundações continuam altos.
\end{abstract}

Palavras-chave: bacia hidrográfica, controle de enchentes, simulação hidrológica.

\section{Urban Occupation and its Hydrologic Impacts in the Upper Mineirinho Watershed}

\begin{abstract}
This work aimed to establish and compare different scenarios of urban occupation and analyze their hydrologic effects. It evaluates downstream flood risks caused by upstream urban growth surrounding the implantation of the new Campus of the University of Sao Paulo - USP in the municipality of Sao Carlos, Sao Paulo state, Brazil. Four scenarios of urban occupation have been depicted: preurbanization (1972); scenario 2000; prospective scenario with Master Plan (until 2025, “CPD”); and expected situation without Master Plan (until 2025, "SPD”). The comparison of the different scenarios was outlined using the hydrologic model IPH II. Hydrologic modeling simulations showed that maximum stream flow discharges of scenario 2025 "SPD" would present an increase of $388.0 \%$ compared with the preurbanization scenario of 1972 and of $319.4 \%$ compared with the scenario 2000. Maximum stream discharges and peak timing of the scenario with Master Plan of 2025 (CPD) would present, respectively, a reduction of $22.3 \%$ and an increase of 50 minutes compared with the scenario without Master Plan of 2025 (SPD).
\end{abstract}

Keywords: watershed, flood risk reduction, hydrologic simulation. 


\section{INTRODUÇÃO E OBJETIVOS}

A degradação de bacias hidrográficas ocorre devido a diversos fatores como: desmatamento, urbanização, obras de terraplenagem, mineração, dentre outros (Dias \& Griffith, 1998). O desenvolvimento urbano frequentemente está associado à substituição de ambientes naturais ou seminaturais por ambientes construídos, com o direcionamento das águas pluviais e dos esgotos para os corpos d'água adjacentes aos canais de drenagem (Haughton \& Hunter, 1994). Como consequência, há aumento do movimento de águas superficiais, além de diminuição da recarga dos aquíferos.

A urbanização de forma desordenada, sem diretrizes de ocupação, impacta gravemente no ciclo hidrológico, pois causa drásticas alterações na drenagem, elevando a possibilidade de ocorrência de enchentes e deslizamentos, impondo riscos à saúde e à vida humana.

No município de São Carlos, SP, mais precisamente na Bacia do Córrego do Mineirinho, encontra-se em fase de implantação o novo Campus da Universidade de São Paulo, denominado Campus 2. A implantação do novo Campus, à montante da Bacia do Mineirinho, tem ocasionado impermeabilização do solo em parte da bacia e fará com que ocorra o aumento do escoamento superficial e da vazão do córrego, contribuindo para aumentar enchentes à jusante.

Este trabalho teve por objetivo principal estabelecer e comparar diferentes cenários de ocupação urbana e seus efeitos no ciclo hidrológico na Bacia do Córrego do Mineirinho.

\section{MATERIAIS E MÉTODOS}

\subsection{Caracterização da área de estudo - Bacia do Córrego do Mineirinho e o Campus 2}

A área de estudo é a parte à montante da Bacia do Mineirinho, que possui área de $3,37 \mathrm{~km}^{2}$ (Figura 1) e apresenta urbanização próxima à cabeceira (nascentes) de dois afluentes que drenam as suas águas para o interior do Campus 2 da USP.

O Campus 2 possui área aproximada de 100,00 ha e abrange em seu terreno $1,8 \mathrm{~km}$ do Córrego do Mineirinho (pertencente à Bacia do Rio Monjolinho), com percurso total de aproximadamente $4 \mathrm{~km}$, quando desemboca no Rio Monjolinho.

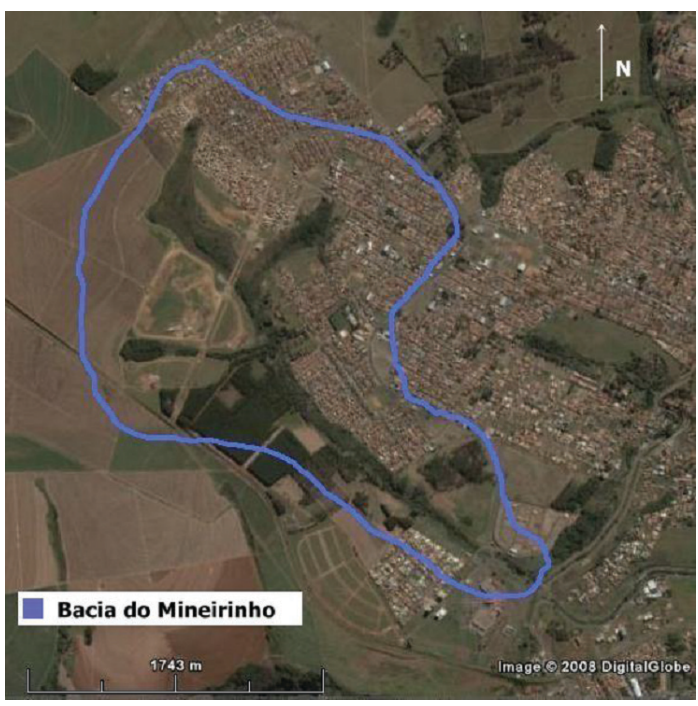

Figura 1. Bacia do Córrego do Mineirinho, onde o Campus 2 da USP encontra-se em fase de implantação. Figure 1. Mineirinho's river watershed, place where the Campus 2 of São Paulo University is building.

\subsection{Cenários ambientais}

As simulações foram aplicadas em diferentes cenários ambientais (Tabela 1). Cenário pré-urbanização (1972), cenário 2000, cenário 2025 sem Plano Diretor e cenário 2025 com Plano Diretor. Após a obtenção dos diferentes cenários, eles foram comparados entre si.

Para a obtenção dos diferentes cenários foi necessário caracterizar o uso e ocupação do solo da parte à montante da Bacia do Córrego do Mineirinho, para isso foi necessária análise de duas fotografias aéreas ortorretificadas (fotointerpretação), feitas em julho de 1972 e agosto de 2000, em escala 1:30.000 (Figura 2), que permitiram a elaboração de mapas através do uso do software AUTOCAD 2000 (Autodesk, 2000).

Dessa forma, foram gerados os cenários pré-desenvolvimento (1972) e cenário 2000 (2000) antes da implantação do Campus 2.

A fotointerpretação (Figura 3) foi feita por meio da sobreposição das fotografias aéreas digitalizadas com os mapas digitais do Campus 2 e da Bacia do Mineirinho, com uso do programa AUTOCAD ${ }^{\circledR} 2000$ (Autodesk, 2000), permitindo que situações visualizadas nas fotografias aéreas, como fragmentos florestais, áreas brejosas, traçado de córregos, áreas agrícolas, áreas urbanizadas e outras situações fossem transpostas para o mapa, como pode ser observado na Figura 3. 

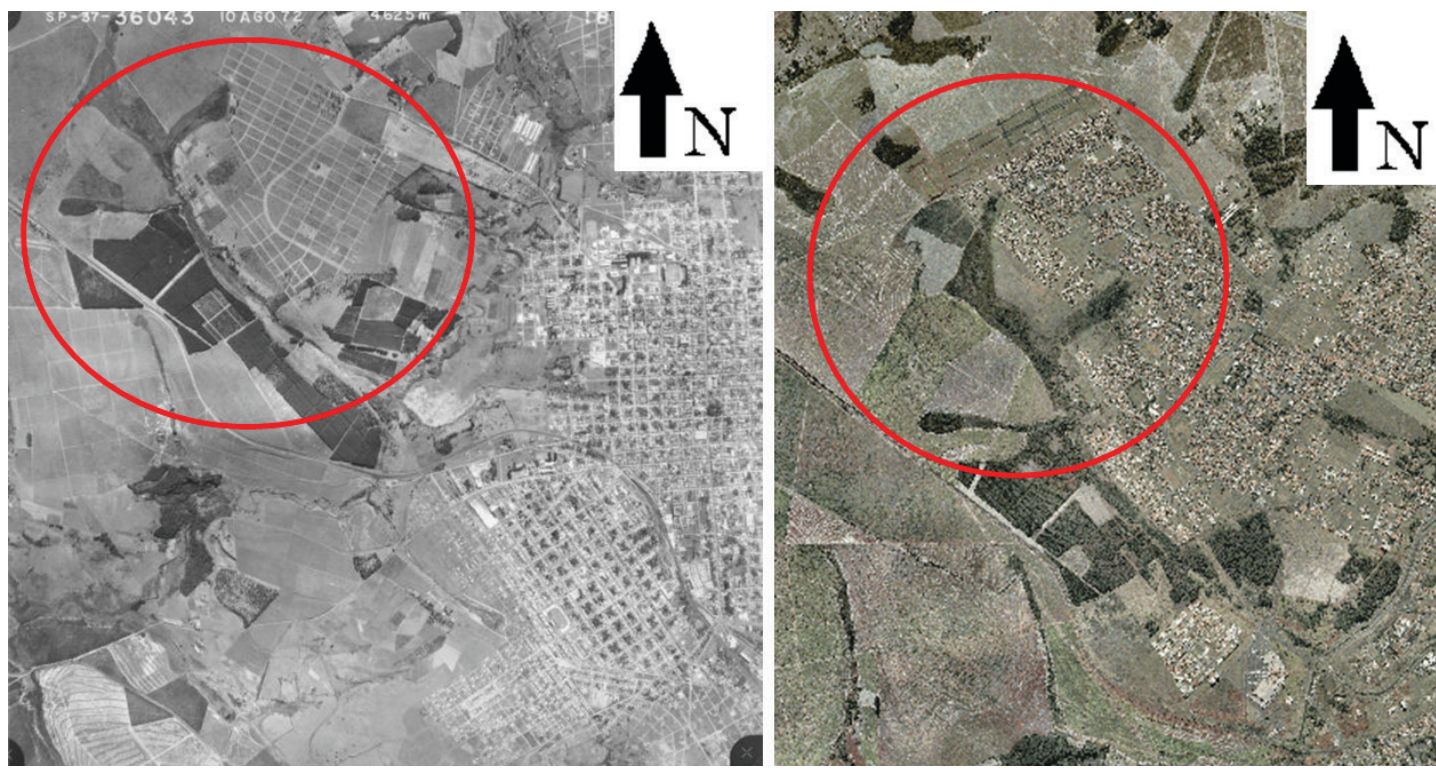

Figura 2. Fotografias aéreas e evolução da urbanização da Bacia do Córrego do Mineirinho nos anos de 1972 e 2000.

Figure 2. Aerial photographs and evolution of the urbanization of the river Mineirinho watershed in the years 1972 and 2000

Tabela 1. Cenários ambientais estudados.

Table 1. Environmental scenarios studied.

\begin{tabular}{ll}
\multicolumn{1}{c|}{ Cenário } & \multicolumn{1}{c}{ Descrição } \\
1- Pré-urbanização & $\begin{array}{l}\text { Situação passada, com menor } \\
\text { interferência antrópica e menor } \\
\text { degradação ambiental (1972) }\end{array}$ \\
2- Situação 2000 & $\begin{array}{l}\text { Antes da implantação do novo } \\
\text { Campus (2000) }\end{array}$ \\
3- Pós-Ocupação & $\begin{array}{l}\text { Previsão da ocupação do Campus } \\
\text { e aumento da urbanização sem } \\
\text { a implantação de Plano Diretor } \\
\text { sem PD }\end{array}$ \\
$\begin{array}{ll}\text { (2025) } \\
\text { 4- Pós-Ocupação } \\
\text { com PD }\end{array}$ & $\begin{array}{l}\text { e aumento da urbanização com } \\
\text { a implantação de Plano Diretor } \\
\text { (2025) }\end{array}$ \\
\hline
\end{tabular}

Os possíveis cenários foram obtidos para situações com e sem Plano Diretor de Ocupação do novo Campus, com e sem vegetação florestal na zona ripária e prevendo-se a impermeabilização das sub-bacias ao longo do tempo, seguindo diretrizes de ocupação previstas no Plano Diretor do Município de São Carlos (São Carlos, 2005).

\subsection{Cenário sem Plano Diretor}

Foi estabelecido um cenário hipotético futurístico, para o ano 2025, sem Plano Diretor, prevendo-se uma ocupação sem normas nem diretrizes.
O crescimento urbano sem diretrizes de ocupação, para o cenário sem Plano Diretor, deverá ser evidenciado nos anos seguintes, ou seja, deverá ocorrer diminuição das áreas permeáveis e algumas alterações na cobertura vegetal, como a extinção das áreas voltadas à produção agrícola e área com presença de pinus.

Alguns remanescentes florestais não foram totalmente retirados desse cenário, pois se acredita que os mesmos só tenham sobrevivido devido a estarem em locais de difícil acesso a maquinários agrícolas e ocupação humana. Além disso, deverá ocorrer implantação de áreas impermeáveis devido à construção do Campus 2 .

\subsection{Cenário com Plano Diretor}

Criou-se um cenário hipotético, também para o ano 2025, com aplicação do Plano Diretor Municipal de São Carlos (PDMSC) e de Plano Diretor de Ocupação (PDO) do Campus 2.

O PDMSC estipula o coeficiente de permeabilidade de $15 \%$ nos novos lotes a serem implantados e o PDO prevê a restauração florestal no interior do Campus 2, de acordo com a legislação ambiental vigente na época (Brasil, 1965) e formação de corredores interligando os remanescentes florestais, conforme proposto por Benini \& Tonissi (2003). 


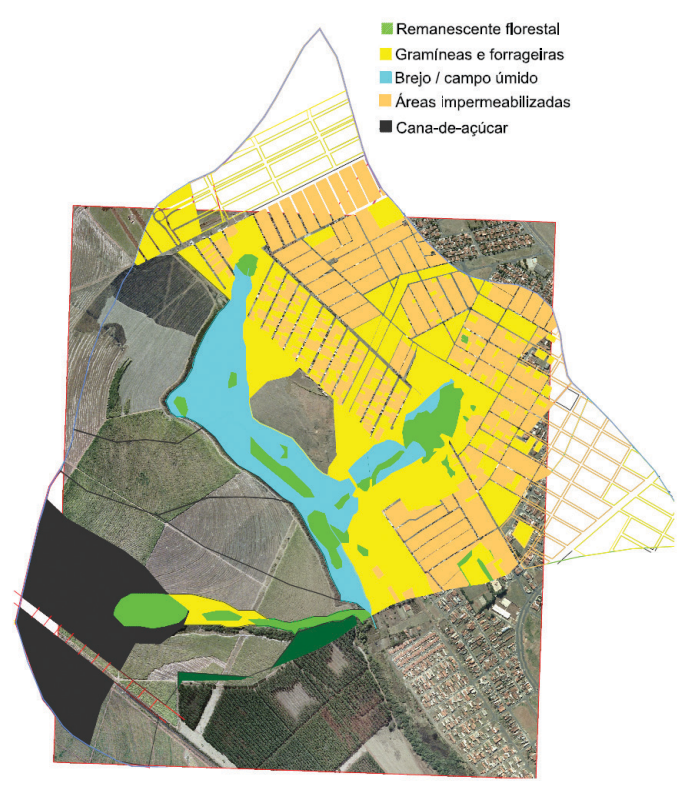

Figura 3. Fotointerpretação, com uso de fotografia aérea e do programa AUTOCAD 2000.

Figure 3. Photointerpretation, using aerial photography and AUTOCAD $^{\circledR} 2000$ software.

\subsection{Simulação hidrológica}

As simulações hidrológicas foram realizadas para todos os cenários, com uso do sistema computacional IPHS-1 para Windows, versão 2.11, desenvolvido pelo Instituto de Pesquisas Hidráulicas da Universidade Federal do Rio Grande do Sul (IPH, 2000). As simulações foram realizadas com o uso do modelo concentrado IPH II.

Os dados de precipitação utilizados foram os observados na estação climatológica do monitoramento ambiental instalada no Campus 2. Foram selecionados os 15 maiores eventos (Tabela 2) ocorridos durante o período de $1^{\circ}$ de novembro de 2004 a 31 de março de 2005. Os dados foram coletados e armazenados no "Data Logger” da estação climatológica de 5 em 5 minutos em eventos de 24 horas (288 intervalos de tempo).

\subsection{Modelo IPH II}

Para realizar as simulações hidrológicas no IPH II (Tucci, 1998), foi necessário discretizar a bacia. Assim, a bacia foi dividida em 10 sub-bacias, de acordo com seu uso e ocupação do solo e em função dos exutórios de interesse.

Para a simulação foi necessário alimentar o modelo com os parâmetros por ele requisitados,
Tabela 2. Eventos observados na Bacia do Mineirinho utilizados para simulação no IPH-II.

Table 2. Events observed in the Mineirinho's watershed used for simulation in IPH-II.

\begin{tabular}{|c|c|c|}
\hline Evento & Data de ocorrência & $\begin{array}{c}\text { Precipitação } \\
(\mathbf{m m})\end{array}$ \\
\hline${ }^{\star} 1$ & 13-14 de novembro de 2004 & 52,0 \\
\hline *2 & 17-18 de novembro de 2004 & 89,0 \\
\hline *3 & 6-7 de dezembro de 2004 & 86,4 \\
\hline *4 & 10-11 de dezembro de 2004 & 60,0 \\
\hline$\star 5$ & 19-20 de dezembro de 2004 & 68,4 \\
\hline *6 & 26 de dezembro de 2004 & 32,2 \\
\hline$* * 7$ & 4-5 de janeiro de 2005 & 91,0 \\
\hline *8 & 6-7 de janeiro de 2005 & 43,6 \\
\hline *9 & 16-17 de janeiro de 2005 & 53,6 \\
\hline *10 & 19 de janeiro de 2005 & 45,2 \\
\hline${ }^{\star} 11$ & 25-26 de janeiro de 2005 & 50,8 \\
\hline$* * 12$ & 27-28 de janeiro de 2005 & 88,2 \\
\hline${ }^{\star} 13$ & 29-30 de janeiro de 2005 & 58,2 \\
\hline${ }^{\star} 14$ & 26 de fevereiro de 2005 & 27,8 \\
\hline${ }^{\star} 15$ & 17-18 de março de 2005 & 26,4 \\
\hline
\end{tabular}

${ }^{*}$ Eventos observados de 5 em 5 minutos durante $24 \mathrm{~h}$.

${ }^{* *}$ Eventos observados de 5 em 5 minutos durante $48 \mathrm{~h}$.

que são (Tucci, 1998): parâmetros do módulo Bacia [Io - capacidade de infiltração quando a umidade é So (início da percolação); Ib - capacidade de infiltração quando o solo está saturado; $\mathrm{h}$ - parâmetro que caracteriza o decaimento da curva exponencial de infiltração e depende das características do solo (Tucci, 1998); Rmax - capacidade de retenção máxima da precipitação; Aimp - porcentagem de área impermeável na bacia; Ks - tempo de retardo do escoamento superficial; $\mathrm{Kb}$ - tempo de escoamento subterrâneo; XN - forma do histograma Tempo, sendo os parâmetros Ks e XN utilizados na propagação do escoamento superficial - método Clark] e parâmetros do módulo Rio [largura (l) e altura do canal (a); as cotas máximas (cmax), mínimas (cmin) e comprimento dos trechos d'água (c) dos trechos de córrego nas sub-bacias; e a rugosidade (n)]. Maiores detalhes sobre os parâmetros utilizados podem ser obtidos em Benini (2005).

Os parâmetros hidrológicos utilizados para a simulação com o IPH II Rmax e Aimp (Tabela 3) variaram em função da ocupação do solo, conforme alterações nos quatro cenários.

Os parâmetros Io, Ib, h, Ks e Kb são parâmetros fixos e não variam entre cenários, conforme observado por Santos et al. (2001), que relatam que, por princípio, 
os parâmetros de infiltração do modelo não devem ser alterados entre cenários, já que o solo não se altera.

Já os parâmetros XN, a, l e c correspondentem à forma da bacia, e os três últimos, às características da seção do curso d'água. Apesar de variarem entre as sub-bacias (Tabela 4), não são alterados entre os cenários.

\section{RESULTADOS E DISCUSSÃO}

\subsection{Cenários ambientais}

\subsubsection{Cenário pré-urbanização (1972)}

O cenário pré-urbanização (1972) apresenta ausência de áreas urbanizadas (Figura 4), com exceção de poucas ruas e vias de terra $(15,31 \mathrm{ha})$, que tinham sido recentemente implantadas. Porém a Bacia do Mineirinho já apresentava características de ações antrópicas, que ocorreram devido à expansão agrícola que fragmentou e suprimiu as áreas de remanescentes florestais em todo Estado de São Paulo (Brito, 1997). Rodrigues \& Gandolfi (2000) relatam que nesse processo de degradação não foram poupadas as áreas de preservação permanente (APPs), sendo que a agricultura sempre foi o principal fator causador de degradação dos ecossistemas ciliares.

Essa realidade já era possível de ser observada no cenário 1972 (Figura 4), no qual se pode observar que a ocupação do solo predominante era a agropecuária (248,60 ha $-73,8 \%$ da Bacia do Mineirinho) e os fragmentos florestais já se encontravam escassos e altamente degradados, com área total de 36,11 ha (10,7\% da área total da Bacia do Mineirinho).

A área correspondente a campo úmido (brejo) era de 24,5 ha (7,3\% da área da bacia), provavelmente ocupada anteriormente por vegetação de mata paludícula, conforme observado atualmente em alguns remanescentes florestais.

Tabela 3. Parâmetros hidrológicos (Rmax e Aimp) em cada sub-bacia para o todos os cenários.

Table 3. Hydrological par ameters (Rmax and Aimp) in each sub-basin for all scenarios.

\begin{tabular}{|c|c|c|c|c|c|c|c|c|}
\hline Sub-bacia & $\begin{array}{c}\text { Rmax } \\
1972\end{array}$ & $\begin{array}{c}\operatorname{Aimp}(\%) \\
1972\end{array}$ & $\begin{array}{c}R \max \\
2000\end{array}$ & $\begin{array}{c}\operatorname{Aimp}(\%) \\
2000\end{array}$ & $\begin{array}{c}R \max \\
2025 \\
\text { SPD }\end{array}$ & $\begin{array}{c}\operatorname{Aimp}(\%) \\
2025 \\
\text { SPD }\end{array}$ & $\begin{array}{c}R \max \\
2025 \\
\text { CPD }\end{array}$ & $\begin{array}{c}\operatorname{Aimp}(\%) \\
2025 \\
\text { CPD }\end{array}$ \\
\hline 1a & 2,50 & 14,9 & 2,53 & 71,38 & 2,60 & 93,07 & 3,49 & 89,7 \\
\hline $1 b$ & 2,89 & 8,0 & 3,15 & 40,72 & 3,82 & 72,89 & 3,92 & 73,0 \\
\hline 2 & 2,57 & 3,5 & 2,61 & 47,13 & 2,71 & 82,28 & 3,90 & 77,2 \\
\hline $3 a$ & 2,55 & 5,4 & 2,54 & 40,78 & 2,87 & 94,23 & 2,89 & 86,2 \\
\hline $3 b$ & 2,60 & 1,3 & 2,64 & 63,34 & 2,94 & 88,49 & 3,82 & 84,3 \\
\hline 4 & 2,56 & 0,8 & 2,80 & 16,91 & 2,56 & 75,66 & 3,90 & 66,5 \\
\hline 5 & 2,73 & 0,9 & 2,86 & 5,02 & 2,73 & 51,84 & 3,66 & 43,4 \\
\hline 6 & 2,89 & 11,0 & 2,85 & 46,23 & 2,51 & 81,72 & 3,24 & 71,5 \\
\hline $7 \mathrm{a}$ & 3,24 & 5,9 & 3,21 & 5,35 & 3,82 & 81,06 & 3,76 & 70,3 \\
\hline $7 b$ & 3,31 & 3,4 & 3,16 & 2,53 & 2,70 & 45,12 & 3,13 & 37,2 \\
\hline
\end{tabular}

Tabela 4. Parâmetros hidrológicos constantes em cada sub-bacia, utilizados para todos os cenários.

Table 4. Hydrological parameters contained in each sub-basin used for all scenarios.

\begin{tabular}{|ccccc|}
\hline Sub-bacia & $\mathbf{X N}$ & $\mathbf{a}$ & $\mathbf{1}$ & $\mathbf{c}$ \\
\hline $1 \mathrm{a}$ & 1,5 & - & - & - \\
\hline $1 \mathrm{~b}$ & 1,5 & 2,0 & 3,0 & 343 \\
\hline 2 & 1,5 & 2,0 & 3,0 & - \\
\hline $3 \mathrm{a}$ & 1,5 & - & - & 123 \\
\hline $3 \mathrm{~b}$ & 1,5 & 1,5 & 2,5 & 425 \\
\hline 4 & 1,0 & 2,0 & 3,5 & 517 \\
\hline 5 & 1,0 & 2,0 & 3,5 & 680 \\
\hline 6 & 1,0 & 2,5 & 2,5 & - \\
\hline $7 \mathrm{a}$ & 1,5 & - & - & 427 \\
\hline
\end{tabular}

C: comprimento do trecho d'água; 1: largura do canal; a: altura do canal. 


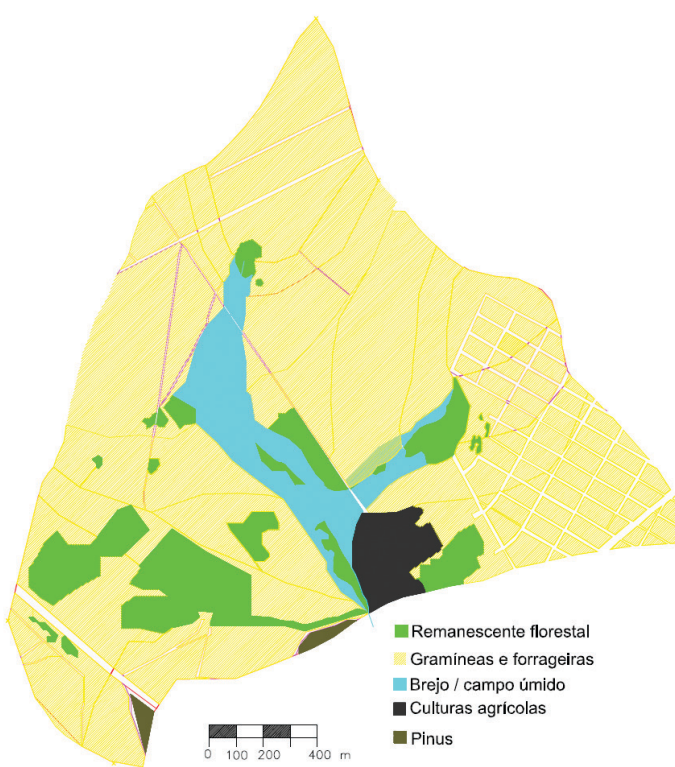

Figura 4. Cenário pré-urbanização (1972).

Figure 4. Scenario before preurbanization (1972).

\subsubsection{Cenário 2000}

A partir dos anos 1980, as cidades com mais de 100 mil habitantes foram as que mais cresceram no Brasil, sendo que hoje $1 / 3$ da população do estado de São Paulo mora em cidades com população entre $100 \mathrm{e}$ 500 mil habitantes (IBGE, 2005).

Nesse contexto, São Carlos se destaca, apresentando em 1980 uma taxa de crescimento anual de 2,57\%, superior à média do estado de São Paulo (São Carlos, 2005).

De fato, essa situação pode ser observada no cenário 2000 (ano 2000), pois o mesmo apresentou drástica mudança no uso e ocupação do solo quando comparado ao cenário 1972. As áreas de pastagem e gramíneas diminuíram de 248,60 ha $(73,08 \%)$ para 86,05 ha $(25,5 \%)$. Por outro lado, surgiram áreas impermeabilizadas devido ao crescimento urbano, correspondentes a 62,57 ha $(18,6 \%$ da área total da bacia - Figura 5). Estimou-se que 33,4\% da área total da bacia era impermeabilizada em 2000, enquanto apenas 5,5\% correspondiam a áreas impermeáveis em 1972.

Nesse cenário foi possível observar a presença de processos erosivos conforme relatado por Benini \& Tonissi (2003), além da presença de despejo clandestino de esgoto e resíduos sólidos, contribuindo para os

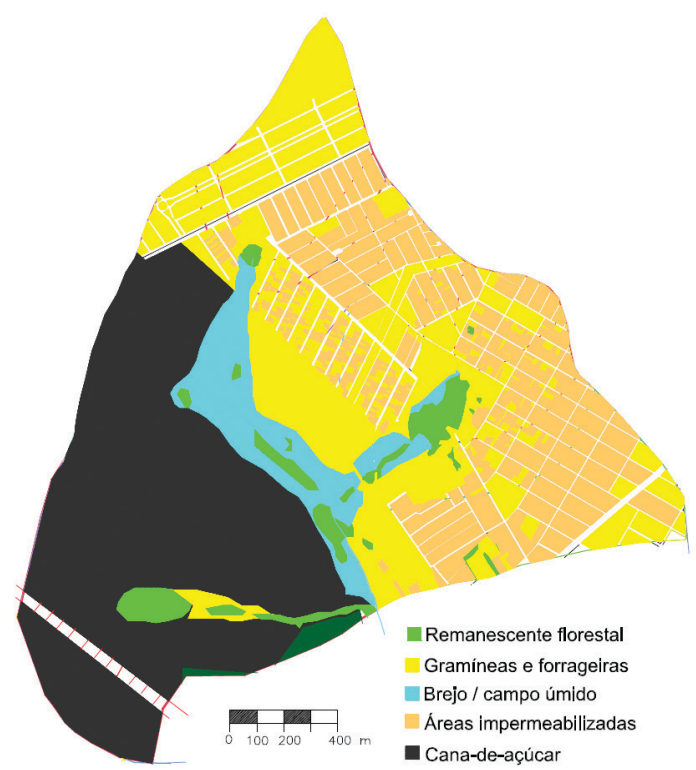

Figura 5. Cenário 2000.

Figure 5. Scenario 2000.

\section{Principais ocupações do solo na Bacia do córrego do Mineirinho}

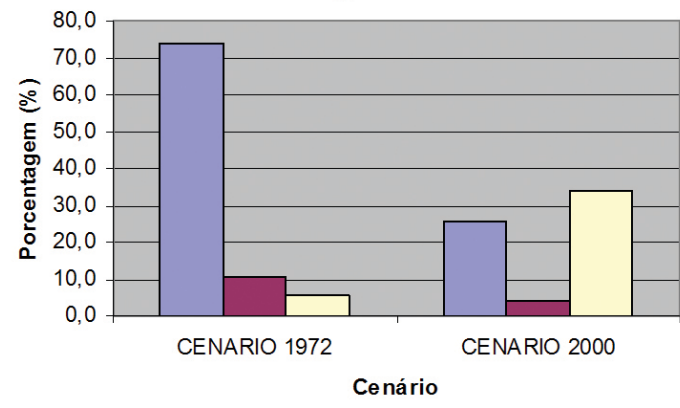

$\square$ pastagens/ gramineas
$\square$ remanescente florestal
$\square$ área impermeável

Figura 6. Evolução das principais ocupações do solo na Bacia do Córrego do Mineirinho nos cenários pré-urbanização 1972 e 2000.

Figure 6. Evolution of the main soil's occupations in the Mineirinho's river watershed in scenarios before urbanization 1972 and 2000.

processos de assoreamento da bacia hidrográfica da região.

Os fragmentos florestais diminuíram significativamente, de 36,11 ha (10,7\% da área total da bacia), no cenário 1972, para 13,43 ha (4,0\% da área total da bacia), no cenário 2000. A Figura 6 apresenta as principais ocupações do solo nos cenários 1972 e 2000. 


\subsubsection{Cenário sem Plano Diretor (2025 SPD)}

O cenário hipotético futurístico para o ano $2025 \mathrm{sem}$ Plano Diretor (SPD) foi estabelecido prevendo-se uma ocupação desordenada, sem normas nem diretrizes, conforme acréscimo observado, nos últimos anos, na Bacia do Córrego do Mineirinho, que cresceu cerca de $80 \%$ em apenas 10 anos.

O crescimento urbano sem diretrizes de ocupação, para o cenário SPD, foi evidenciado e nele ocorreu diminuição das áreas permeáveis. No cenário 2025 SPD a porcentagem de área impermeável foi estimada em $76,64 \%$ da área total da bacia, contrastados com os 33,4\% em 2000 e com os apenas 5,5\% em 1972.

A área com presença de lotes urbanizados no cenário 2025 SPD corresponde a 189,68 ha (56,3\% da bacia), enquanto no cenário 2000 ela apresenta 62,57 ha (18,6\% da bacia), ou seja, um crescimento de aproximadamente $303 \%$.

Nesse cenário previu-se a erradicação de áreas com cultivo agrícola eárea com presença de pinus (Figura 7).

Alguns remanescentes florestais não foram totalmente suprimidos desse cenário pois se acredita que tenham sobrevivido até o cenário 2000 devido a estarem em locais de difícil acesso a maquinários agrícolas e ocupação humana.

Além disso, nesse cenário previu-se a implantação de áreas impermeáveis devido à construção do Campus 2, para o qual se estimou uma área construída com 18,51 ha (5,5\% da área da bacia), correspondentes a prédios, estacionamentos, vias e ciclovias e demais ocupações do Campus.

\subsubsection{Cenário com Plano Diretor (2025 CPD)}

O cenário 2025 CPD (Figura 8) foi estabelecido prevendo-se o crescimento da urbanização porém levando-se em consideração a aplicação das diretrizes estabelecidas no Plano Diretor Municipal de São Carlos (PDMSC) e do Plano Diretor de Ocupação (PDO) do Campus 2.

O PDMSC 2004 estipula o coeficiente de permeabilidade de $15 \%$ nos novos lotes a serem implantados na região onde se localiza a Bacia do Córrego do Mineirinho.

Esse cenário também prevê a criação de novas áreas impermeáveis no interior do Campus devido à sua implantação, porém de forma mais controlada

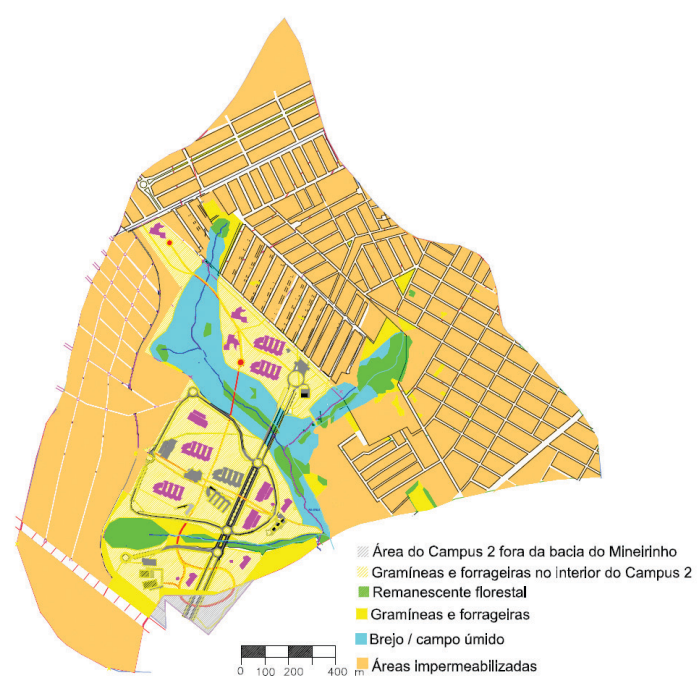

Figura 7. Cenário 2025 sem Plano Diretor.

Figure 7. Scenario 2025 without a Master Plan.

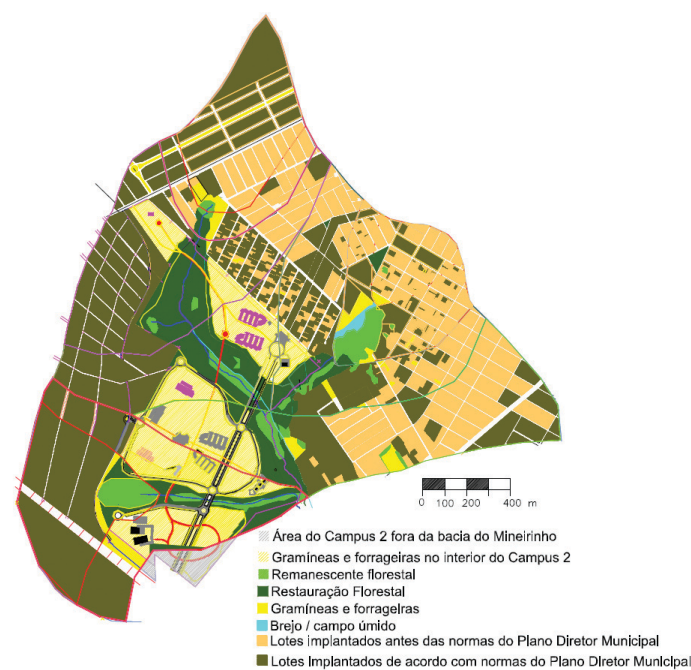

Figura 8. Cenário com Plano Diretor (2025).

Figure 8. Scenario Master Plan (2025).

quando comparada à implantação do Campus no cenário 2025 SPD.

A urbanização do Campus 2, nesse cenário, foi estimada em 10,40 ha (3,1\% da área total da bacia), enquanto no cenário SPD a área de construções no interior do Campus 2 foi de 18,51 ha (5,5\% da área da bacia).

No cenário 2025 CPD haverá um aumento nas áreas de remanescentes florestais (Figura 9). Estima-se que 46,71 ha $(13,9 \%)$ da área total da bacia será coberta 
por vegetação florestal, enquanto no cenário 2025 SPD apenas 10,86 ha $(3,2 \%)$ seriam cobertos por vegetação de porte arbóreo (Figura 9).

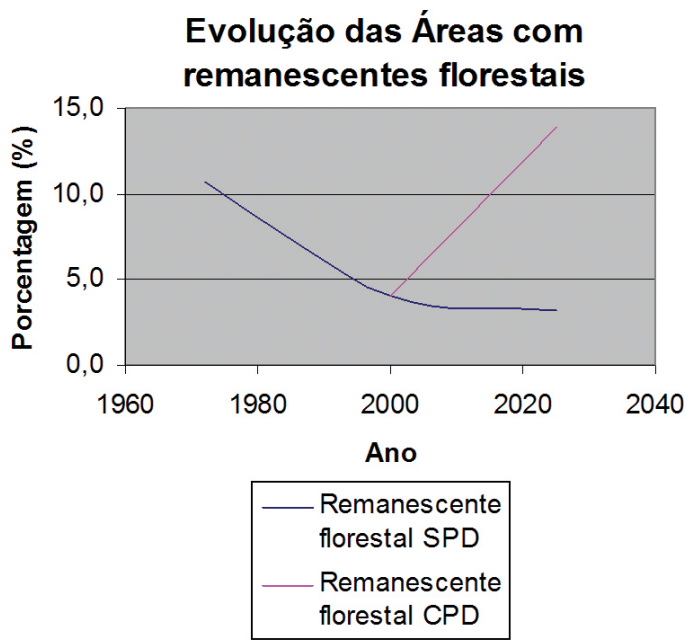

Figura 9. Evolução das áreas com remanescentes florestais na Bacia do Córrego do Mineirinho com plano diretor (CPD) e sem plano diretor (SPD).

Figure 9. Evolution of the remaining forest areas in the Mineirinho's watershed with Master Plan (CMP) and no master plan (SPD).

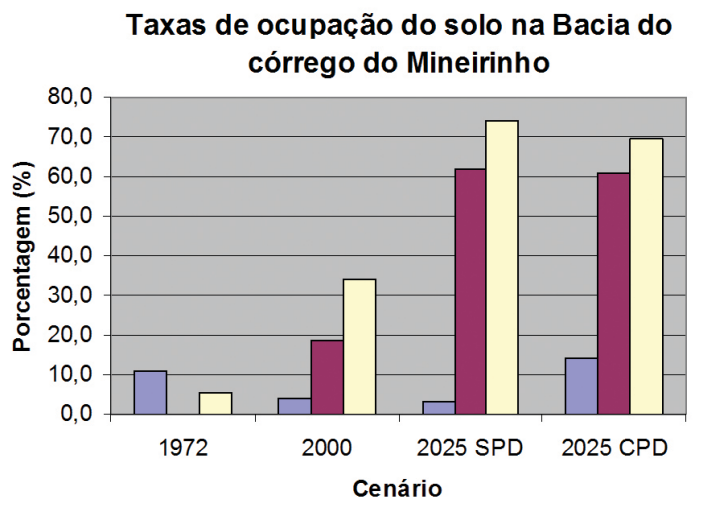

\begin{tabular}{l}
\hline Remanescente Florestal \\
$\square$ Urbanização \\
$\square$ Área Impermeável
\end{tabular}

Figura 10. Evolução das principais ocupações do solo na Bacia do Córrego do Mineirinho no cenário pré-urbanização (1972), cenário 2000, cenário 2005 SPD e cenário 2005 CPD.

Figure 10. Evolution of the main soil's occupations in the Mineirinho's watershed before urbanization (1972) scenario, Scenario 2000 Scenario 2005 Scenario 2005 SPD and CPD.
A urbanização nesse cenário corresponde à urbanização já implantada até o cenário 2000 (62,57 ha), somada à urbanização CPD (127,13 ha), totalizando 189,70 ha, ou seja, a área urbanizada é a mesma que no cenário 2025 SPD, porém, no cenário CPD prevê-se 15\% a mais de áreas permeáveis para as novas ocupações.

No 2025 CPD, o total porcentual de áreas impermeáveis seria de $66,40 \%$, enquanto no cenário SPD seria de $76,64 \%$ da área total da bacia, que contrastam com os $33,4 \%$ de 2000 e com os apenas 5,5\% de 1972 .

Na Figura 10 pode-se observar a evolução das taxas de ocupação do solo na Bacia do Córrego Mineirinho para os quatro cenários estudados. Ressalta-se que a urbanização não existia no cenário 1972 e que no cenário 2025 SPD e CPD a taxa de urbanização será praticamente a mesma, porém que no cenário $2025 \mathrm{CPD}$ deverá ocorrer diminuição de áreas impermeáveis quando comparadas às do SPD, devido a $15 \%$ das áreas destinadas a novos lotes serem necessariamente permeáveis, conforme diretrizes do PDMSC 2004.

\subsection{Simulações hidrológicas}

A Figura 11 apresenta as vazões simuladas no exutório final da Bacia do Mineirinho, para o evento 2 (Tabela 2, já apresentada), em todos os cenários. Dessa forma, torna-se claro que as vazões crescem significativamente conforme a urbanização da bacia, assim como o tempo de pico tende a diminuir. Ou seja, o escoamento superficial é mais rápido e mais intenso conforme a bacia é impermeabilizada.

É interessante observar que no cenário 1972, quando não havia urbanização mas a bacia já se apresentava antropizada, a vazão era de $2,57 \mathrm{~m}^{3} / \mathrm{s}$ e o tempo de pico era de 685 minutos. No cenário 2000 ocorre aumento da vazão para $4,82 \mathrm{~m}^{3} / \mathrm{s}$ e o tempo de pico cai para 170 minutos. Ou seja, há um incremento na vazão máxima de $87,5 \%$ de um cenário para o outro e o tempo de pico decai 515 minutos (8,6 horas).

De forma similar ao observado na simulação com o evento 2, no evento 3 (Tabela 2 ) as vazões máximas e o tempo de pico tendem a se alterar em função da taxa de impermeabilização do solo.

No cenário 2025 SPD a vazão máxima simulada seria de $12,93 \mathrm{~m}^{3}$ /s e o tempo de pico, de 65 minutos. Portanto, nesse cenário a vazão máxima cresce 388,0\% quando comparada ao cenário 1972 e 319,4\% quando comparada 


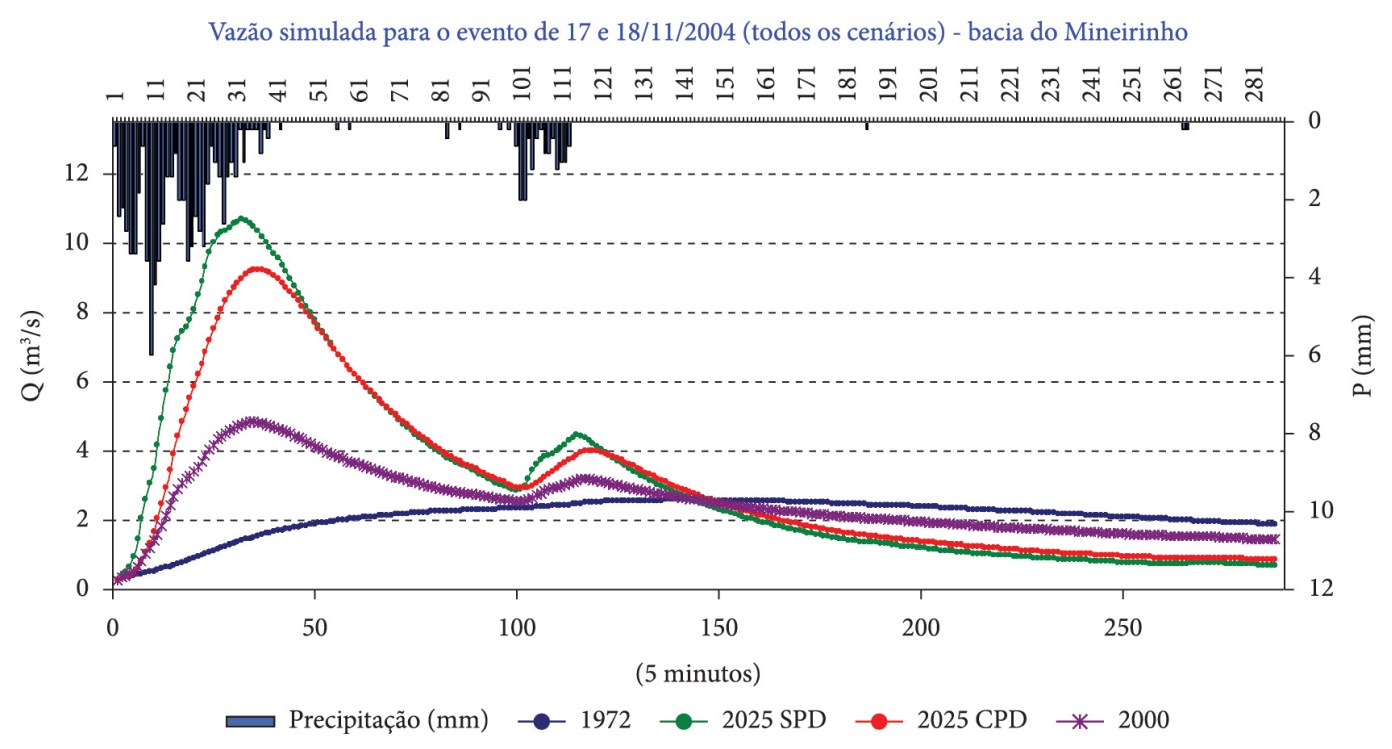

Figura 11. Simulação para todos os cenários, para o evento 17 e 18 de nov/2004 (Bacia do Mineirinho - 89 mm). Figure 11. Simulation for all scenarios, event 17 and 18 Nov/2004 (Mineirinho's watershed - $89 \mathrm{~mm}$ ).

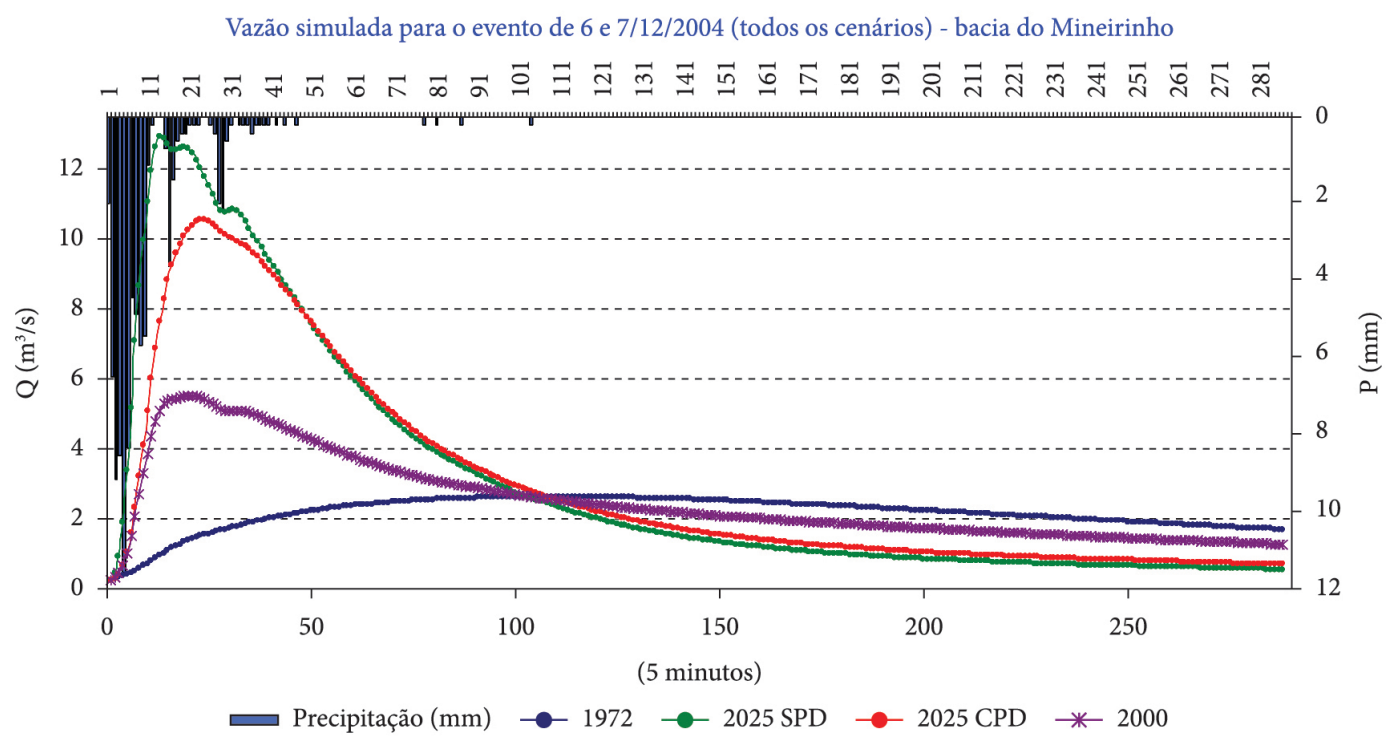

Figura 12. Simulação para todos os cenários, para o evento 6 e 7 de dez/2004 (Bacia do Mineirinho - 86,4 mm). Figure 12. Simulation for all scenarios, event 6 and 7th November /2004 (Mineirinho's watershed - 89 mm).

ao cenário 2000. E o tempo de pico diminui 465 minutos e 35 minutos, respectivamente, quando comparado aos dos cenários 1972 e 2000 (Figura 12).

No cenário $2025 \mathrm{CPD}$, a vazão seria de 10,57 m³ $/ \mathrm{s} \mathrm{e}$ o tempo de pico, de 115 minutos. Ou seja, entre os cenários 2025 CPD e 2025 SPD há uma diminuição de 22,3\% na vazão máxima e o decréscimo no tempo de pico é de 50 minutos (Figura 13).

Quando comparamos as vazões máximas simuladas para o cenário 2025 SPD e 2025 CPD, para o evento 5 (Tabela 2 e Figura 14), observa-se que se forem seguidas as diretrizes dos PDMSC e PDO do Campus 


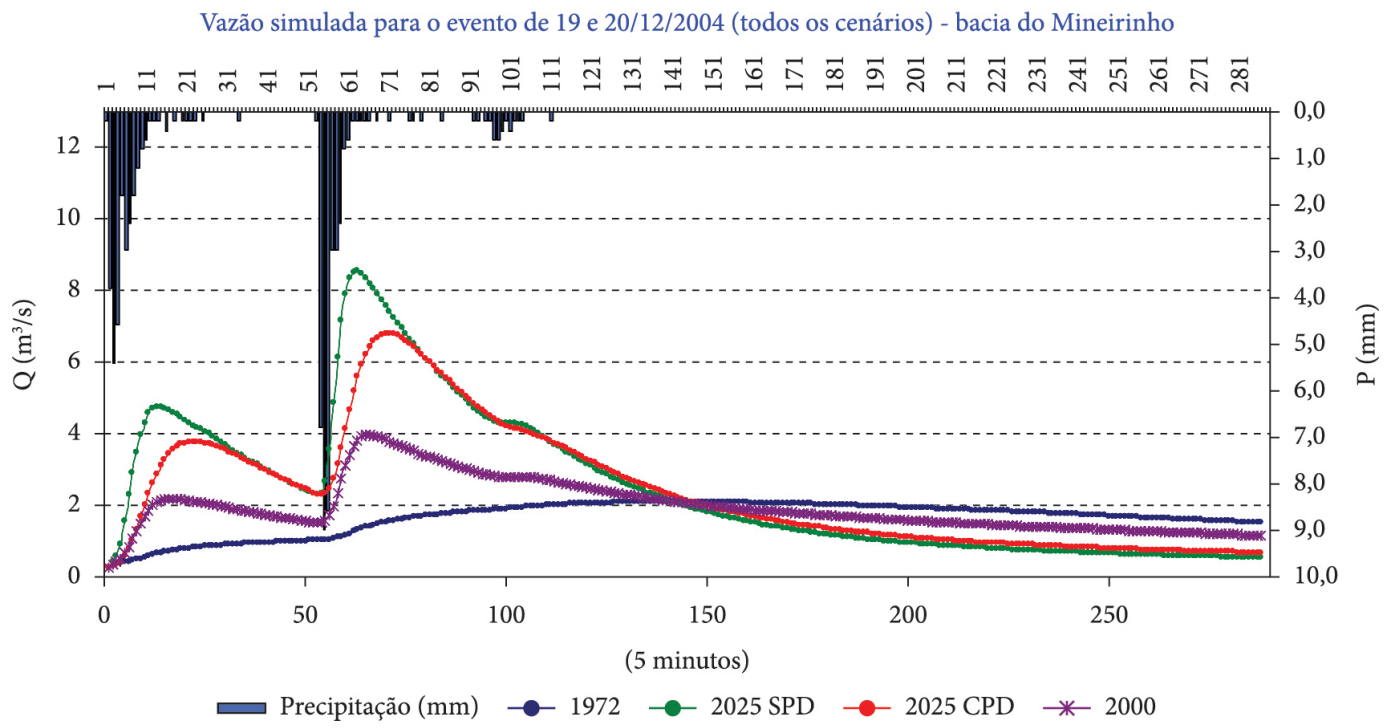

Figura 13. Simulação para todos os cenários, para o evento 19 e 20 de dez/2004 (Bacia do Mineirinho - 98,9 mm). Figure 13. Simulation for all scenarios, event 19 and 20th December /2004 (Mineirinho's watershed - 89 mm).

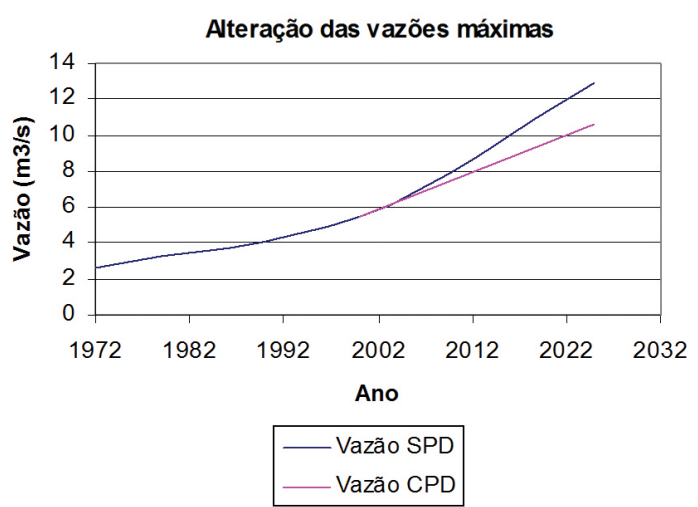

Figura 14. Alterações nas vazões máximas em função dos cenários.

Figure 14. Changes in peak flows according to the scenarios.

2 as vazões máximas poderão abaixar de 8,53 para $6,88 \mathrm{~m}^{3} / \mathrm{s}(24,0 \%)$. E o tempo de pico poderia ser aumentado de 315 para 355 minutos (40 minutos). Isso implica afirmar-se que, apesar de as vazões máximas ainda apresentarem-se relativamente altas quando comparadas aos cenários 2000 e 1972, essa redução no tempo de pico em 40 minutos pode contribuir com as pesquisas hoje realizadas para elaboração de um sistema de alerta ambiental em tempo real.

Pesquisas desenvolvidas em microbacias experimentais demonstraram que o uso e ocupação do solo e os diversos tratamentos aplicados à cobertura vegetal afetam tanto a quantidade do deflúvio produzido quanto o regime de vazão das microbacias. Em certas situações, a quantidade de água do deflúvio pode aumentar pelo manejo da vegetação, em outras condições os picos de vazão podem ser reduzidos (Reinhart \& Pierce, 1964 apud Rodriguez Anido, 2002).

Considerando-se microbacias onde o uso da terra não tenha favorecido o surgimento de áreas compactadas ou impermeáveis nas quais poderia ocorrer escoamento superficial hortoniano durante as chuvas, as zonas ripárias desempenham papel hidrológico fundamental na geração do escoamento direto e por essa razão tais áreas devem estar permanentemente protegidas pela vegetação ciliar (Lima \& Zakia, 2000).

Dessa forma, o aumento da cobertura vegetal, conforme proposto por Benini \& Tonissi (2003), e a limitação das áreas impermeáveis que deverão ser respeitadas em cada lote, em função das diretrizes do PDMSC, seriam suficientes para diminuir de 15,8\% a 24\% (dependendo da intensidade da precipitação) as vazões máximas que deveriam ocorrer se nenhuma diretriz for seguida (cenário 2025 SPD).

No entanto, é possível observar que, mesmo seguindo diretrizes do PDMSC e do PDO do Campus 2, os efeitos na diminuição da vazão e controle de 
enchentes à jusante seriam pouco significativos, pois o ideal seria atingir valores de vazão máxima próximos aos obtidos nas simulações para o cenário 1972 ou, pelo menos, do cenário 2000.

Esses dados evidenciam a influência da urbanização na drenagem de pequenas bacias hidrográficas e comprovam as alterações no seu ciclo hidrológico.

A Figura 14 apresenta as alterações na vazão máxima ao longo dos quatro cenários para o evento 3. No presente estudo foi possível observar que as vazões máximas tiveram um aumento de $108 \%$ do cenário 1972 para o cenário 2000, sendo que a variação de área impermeável foi de 284\%. Do cenário 1972 ao 2025 SPD houve aumento de $388 \%$ e o crescimento de áreas impermeáveis, nesse período, seria de 71,1\%. Quando comparamos o cenário 1972 ao cenário 2025 CPD, o acréscimo nas vazões seria de 299\% e a variação de áreas impermeáveis, de 60,9\%.

Dessa forma, com a redução de 10,24\% nas áreas impermeáveis, que deve ser a diferença entre cenário CPD e cenário SPD, pode haver diminuição em 18,3\% no valor das vazões máximas observadas.

\section{CONCLUSÕES E RECOMENDAÇÕES}

Torna-se claro que as diretrizes previstas para o cenário CPD não são suficientes para conter a ocorrência de inundações. Dessa forma, além da recuperação das zonas ripárias e da manutenção da permeabilidade em 15\% nos lotes, seriam necessárias medidas mais drásticas, tais como elaboração de planos diretores municipais que contemplem sistemas adequados de drenagem, reuso de águas pluviais, implantação de microreservatórios nos lotes, além de reestruturação na arborização urbana e em áreas verdes.

Quanto mais se prevê a ocupação urbana sem diretrizes, maiores serão as ocorrências de enchentes e, consequentemente, de prejuízos causados por inundações. Assim, pode-se verificar a fragilidade hidrológica das bacias hidrográficas em relação à impermeabilização do solo e torna-se fácil perceber a razão do crescimento de enchentes nas regiões urbanas do país.

Diante dos hidrogramas apresentados para os cenários de tendência, observa-se progressivamente o crescimento das vazões máximas. Assim, a impermeabilização do solo e a diminuição de fragmentos florestais diminuíram o tempo de pico e elevaram a vazão máxima em todas as sub-bacias.

Recomenda-se a restauração florestal da zona ripária para a mitigação de enchentes e controle de sedimentos. Sugere-se ainda que pelo menos $20 \%$ da área total da bacia sejam ocupados por vegetação florestal, para atenuar os picos de cheia e os volumes de vazão máxima. Recomenda-se que seja realizado um sério programa de arborização urbana, tendo em vista que a copa das árvores apresenta excelente capacidade de retenção de águas pluviais.

Por fim, recomenda-se que a vazão real no Córrego do Mineirinho continue a ser monitorada, de forma a possibilitar a comparação com os resultados aqui apresentados, de modo que se possa avaliar a aplicação do Modelo IPH II como ferramenta de apoio à tomada de decisões e prevenção de desastres naturais urbanos.

\section{STATUS DA SUBMISSÃO}

Recebido: 24 jun., 2014

Aceito: 10 out., 2014

\section{AUTOR(ES) PARA CORRESPONDÊNCIA}

\section{Rubens de Miranda Benini}

Departamento de Hidráulica e Saneamento, Universidade de São Paulo - USP, CEP 13566590, São Carlos, SP, Brasil

e-mail: rubensbenini@yahoo.com.br

\section{REFERÊNCIAS}

Autodesk. AUTOCAD $D^{\circledR} 2000$.

Benini RM. Cenários de ocupação urbana e seus impactos no ciclo hidrológico na bacia do córrego do Mineirinho [dissertação]. São Carlos: EESC-USP; 2005.

Benini, R. M., Tonissi, F. B. Projeto de restauração florestal do Campus II. São Carlos: USP; 2003. p. 27. Licença Ambiental, cap. 3.

Brasil. Lei $n^{\circ}$ 4.771, de 15 de setembro de 1965. Institui o novo Código Florestal. Alterada pela Lei $n^{\circ} 7.803$ de 18 de julho de 1989 e pela medida provisória n. ${ }^{\circ} 1605-30$, de 19 de novembro de 1998. Diário Oficial da República Federativa do Brasil, Brasília, DF (1965 set.). [cited 2014 Apr 10]. Available from: http://www.jundiai.sp.gov.br/ secretarias/smpma/leis/codigoflorestal.pdf. 
Brito MCW. Cerrado: bases para a conservação e uso sustentável das áreas de cerrado do Estado de São Paulo. São Paulo: SMA; 1997.84 p.

Dias LE, Griffith JJ. Conceituação e caracterização de áreas degradadas. In: Dias LE, Mello JWU, editores. Recuperação de áreas degradadas. Viçosa: UFV; 1998. p. 1-7.

Haughton G, Hunter C. Sustainable cities. London: Jessica Kingsley Publishers and Regional Studies Association; 1994. 357 p. Regional Policies and Development Series n. 7.

Instituto Brasileiro de Geografia e Estatística - IBGE. [cited 2005 Apr 10]. Available from: www.ibge.gov.br.

Instituto de Pesquisas Hidráulicas - IPH. IPHS-1 $1^{\oplus}$. Porto Alegre; 2000. [cited 2005 Apr 13]. Available from: www. iph.ufrgs.br/iphs1.

Lima WP, Zakia MJB. Hidrologia de matas ciliares. In: Rodrigues RR, Leitão Filho HF, organizadores. Matas ciliares: conservação e recuperação. São Paulo: EDUSP; 2000. p. 33-44. vol. 1.
Reinhart, K. G., \& Pierce R. S. Stream-gaging stations for research on small watersheeds. Washington: USDA Forest Service; 1964. p. 1-37. Agricultural Handbook n. 268.

Rodrigues RR, Gandolfi S. Conceitos, tendências e ações para a recuperação de florestas ciliares. In: Rodrigues RR, Leitão Filho HF, organizadores. Matas ciliares: conservação e recuperação. São Paulo: EDUSP; 2000. p. 235-247. vol. 1.

Rodriguez Anido NM. Caracterização hidrológica de uma microbacia experimental visando identificar indicadores de monitoramento ambiental [dissertação]. Piracicaba: ESALQ-USP; 2002.

Santos RJL, Tucci CEM, Silveira ALL, Meneses Filho AS. Estimativa do hidrograma de projeto com base na incerteza dos parâmetros do modelo. Revista Brasileira de Recursos Hídricos 2001; 6: 29-41.

São Carlos. Prefeitura Municipal de São Carlos - PMSC. Câmara Municipal de São Carlos. Lei no 13.691, de 25 de novembro de 2005. Plano Diretor de São Carlos I: diagnóstico da cidade. 2005. Proc. 2146/03.

Tucci CEM. Modelos hidrológicos. Porto Alegre: ABRH; 